\title{
Isolation and Culture Condition Optimization of Chlorella vulgaris
}

\author{
U. Rai ${ }^{1}$, G. Deshar ${ }^{1}$, B. Rai ${ }^{1}$, K. Bhattarai ${ }^{1}$, R. P. Dhakal ${ }^{2}$ and S. K. Rai ${ }^{3}$ \\ ${ }^{1}$ Asian Institute of Technology and Management, Lalitpur \\ ${ }^{2}$ Nepal Academy of Science and Technology (NAST), Lalitpur \\ ${ }^{3}$ Post Graduate Campus, Tribhuvan University, Biratnagar \\ e-mail: keshab.bhattrai@gmail.com
}

\begin{abstract}
Chlorella vulgaris Beyerinck (Beijerinck) is one of the fast growing planktonic microalgae predominantly found in lentic habitats. It was isolated from water samples using BG 11 medium and identified and screened for mixotrophic growth using glucose as carbon source in the medium. The growth of this algae was also studied for autotrophic and mixotrophic regimen. It showed higher growth in a medium of $\mathrm{pH} 7$ containing glucose rather than in autotrophic condition. Similarly, its growth was also studied in media containing different nitrogen sources in which $\mathrm{NaNO}_{3}$ gave the best result. A pilot scale culture of $C$. vulgaris was performed in $5 \mathrm{l}$ fermenter illuminated with fluorescent tube of $36 \mathrm{~W}$ maintaining 16:8 hrs of light and dark period with $\mathrm{pH} 7$, temperature at $25^{\circ} \mathrm{C}$, stirrer rate at $75 \mathrm{rpm}$, air flow rate at $30 \mathrm{~L} / \mathrm{hr}$. The specific growth rate was found to be 6.879 cells/ $\mathrm{ml} /$ day whereas doubling time was found to be 2 hrs and 9 mins. The cells were harvested by sedimentation and centrifugation followed by drying at $50^{\circ}-$ $80^{\circ} \mathrm{C}$. The dried biomass was treated with dichloromethane: methanol (2:1) v/v solution in Soxhlet extractor for 3-4 hrs followed by evaporation and extraction of non-polar lipid by hexane. The total lipid obtained was $15.53 \%$.
\end{abstract}

Key words: biofuel, Chlorella vulgaris, microalgae, mixotrophy

\section{Introduction}

Chlorella vulgaris Beyerinck (Beijerinck) is a green coccoid species of single celled fresh water microalgae belonging to Chlorellaceae family. The cells are slightly ellipsoidal to spherical in shape, about 2 to 10 ì m in diameter. The cells are without flagella and have thin cell wall. It can grow prolifically doubling its biomass weight in few hr of sunlight. So, $C$. vulgaris is known as one of the fastest growing microalgae and includes a reasonable amount (14-30\%) of triacylglycerol. The oil yield in microalgae can exceed $75 \%$ by weight of dry biomass under different circumstances (Christi 2007, Hu et al. 2008). Chlorella contains green photosynthetic pigments known as chlorophyll-a and -b in its chloroplasts. Through photosynthesis, it multiplies rapidly, requiring only carbon dioxide, water, sunlight, and a small amount of minerals to reproduce. Chlorella has much higher utilization rate (10-20\%) of light energy for photosynthesis when compared to common plants (Zhang et al. 2000). According to
Belasco (1997) and Zelitch (1971), it contains 45\% protein (w/w, dry basis), 20\% fat, 20\% carbohydrates, $5 \%$ fibre and $10 \%$ minerals and vitamins. Chlorella is the richest source of chlorophyll which is widely used as a health food and feed supplement, as well as in the pharmaceutical and cosmetics industry (Sharma et al. 2011). It has been produced commercially in several countries for its use as neutraceutical food and medicinal purpose due to its valuable contents particularly pigments and proteins (Sharma et al. 2011). Similarly Â-1, 3-glucan is one of the most important substances in Chlorella with a good capacity for scavenging radicals and reducing blood lipids. This compound is also an immunostimulator. It has also indicated certain health benefits in gastric ulcers and wounds and prevents atherosclerosis, hypercholesterolemia and tumour effects (Spolore et al. 2006). Production of algal biomass can be worthwhile when considering the high-value 
metabolites that can be obtained from these sources. However, lipids content in C. vulgaris under general growth conditions is up to $\sim 20 \%$ by weight of dry biomass (Illman et al. 2000). Mixotrophic algae can grow both autotrophically and heterotrophically. It could undergo photoautotrophic, photoheterotrophic, heterotrophic as well as mixotrophic metabolism (Edberg 2010).

Compared with other superior plants, microalgae have higher photosynthetic efficiency, higher biomass productivities, faster growth rates and higher ability to fix $\mathrm{CO}_{2}$ with an efficiency of 10-15 times more. This aspect, together with high intracellular lipid content, can potentially make a number of unicellular algae species among the most efficient producers of lipids of the planet (Scarsella et al. 2010). The use of algae as energy crops has potential, due to their easy adaptability to growth conditions, the possibility of growing either in fresh or marine waters and avoiding the use of land (Khola \& Ghazala 2012).

\section{Methodology}

\section{Isolation, identification and preservation}

Water samples were collected from the College premises of AITM, Khumaltar, Lalitpur, Nepal and also from ponds of Godavari Lalitpur, Nepal. pH of the water samples were measured with $\mathrm{pH}$ meter. Samples were serial diluted and cultured in the modified BG11 medium (Geeta \& Rani 2011). Instead of ferric ammonium citrate, ferric citrate and ammonium sulphate were added in the BG 11 medium. The C. vulgaris was identified by microscopic observation and photomicrograph. Since it is necessary to preserve the culture as a stock, cryovials filled with sterile glycerol inoculated with axenic culture of $C$. vulgaris and stored at $-20^{\circ} \mathrm{C}$ refrigerator.

\section{pH optimisation}

The effect of $\mathrm{pH}$ on growth of the algae was studied using modified BG 11 media in the $\mathrm{pH}$ range of 4, 5, 6 , 7, 8, 9 in $250 \mathrm{ml}$ conical flasks. All the flasks were inoculated uniformly at $15 \%(\mathrm{v} / \mathrm{v})$ inoculum and incubated at $25 \pm 1{ }^{\circ} \mathrm{C}$ temperature and 16:8 hrs light: dark cycle. Optical density (using spectrophotometer) and cell count (using hemocytometer) were done every $24 \mathrm{hrs}$. After 10 days of culture, the cells were harvested by sedimentation, centrifugation and drying on oven and dry weight was measured (Dayananda et al. 2007).

\section{Selection of growth regimen}

For observing the autotrophic and mixotrophic growth condition of $C$. vulgaris, the algae were cultured in BG11 medium with and without glucose. $\mathrm{pH}$ of both the mediums were adjusted and sterilized. The medium with glucose was inoculated and incubated in the incubator at $25^{\circ} \mathrm{C}$ without light whereas the culture flask without glucose was incubated at $25^{\circ} \mathrm{C}$ with fluorescent illumination with light and dark ratio of 16:8 hours. The biomass in each culture flasks were determined by observing the optical density at $686 \mathrm{~nm}$ at regular interval of time i.e. $24 \mathrm{hrs}$.

\section{Selection of nitrogen source}

Suitable nitrogen source for optimum algal growth was determined by subjecting the algal culture to media containing different sources of nitrogen such as $\mathrm{NaNO}_{3}$, $\mathrm{KNO}_{3}, \mathrm{NH}_{4} \mathrm{NO}_{3}$, urea and nitrogen deficient. Culture flasks with sterile medium were inoculated and incubated in the environmental chamber at $25^{\circ} \mathrm{C}$, with fluorescent illumination. Optical density (686 nm) and cell counts were done. Dry cell weight was recorded after harvesting.

\section{Scaling up and biomass production}

The fermenter used for the experiment was biotech-5BG fermenter (Baoxing Bio-engineering equipment Co., ltd (BXBIO)) for algal culture application. In the present investigation fermenter of working volume $5.0 \mathrm{~L}$ was used. Basal heating system and an internal cooling coil was used to maintain $25^{\circ} \mathrm{C}$. The power controller module has the controls for the temperature, agitation, rotameter and cooling water valve. Additional control module includes $\mathrm{pH}$, level controller. $1 \mathrm{~N} \mathrm{HCl}$ acid and $1 \mathrm{~N} \mathrm{NaOH}$ were used to control the $\mathrm{pH}$. A program was set with input of necessary parameters set values and the fermentation time was set to 6 days.

\section{Fermenter sterilization}

The fermenter vessel was filled with growth media BG11 with glucose (3L). Finally the whole fermenter vessel along with the media inside was placed inside an autoclave (YXQ-LS-SII vertical type autoclave) and sterilized. The acid and the alkali were also autoclaved.

\section{Inoculum preparation and culture}

About $15 \%$ of the algal suspension was inoculated into the fermenter vessel. All the parameters in the fermenter were set as shown in Table 1. with 16:8 hrs of light: dark period through external fluorescent tube light. 
Table 1. Setting fermenter parameters

\begin{tabular}{c|c|c}
\hline S.N & Parameters & Set value \\
\hline l. & Pressure & $0.05 \mathrm{MPa}$ \\
$\mathbf{2 .}$ & Air flow rate & $30 \mathrm{~L} / \mathrm{hr}$ \\
$\mathbf{3 .}$ & Rate of stiming & $75 \mathrm{RPM}$ \\
$\mathbf{4 .}$ & $\mathrm{O}_{2}$ Saturation & $50 \%$ \\
$\mathbf{5 .}$ & $\mathrm{pH}$ & 7 \\
$\mathbf{6 .}$ & Temperature & $25^{\circ} \mathrm{C}$ \\
\hline
\end{tabular}

\section{Biomass estimation}

The biomass in each culture flask as determined by measuring optical density at $686 \mathrm{~nm}$, cell count and dry cell weight.

Biomass $(\mathrm{g} \cdot \mathrm{ml})=\frac{\begin{array}{l}\text { Wi. of falcon tube with biomass }(-) \\ \text { Wi. of empty falcon tube }\end{array}}{\text { Volume of sample (mi) }}$

\section{Determination of growth rate}

The exponential (straight line) phase of growth was carefully determined and specific growth rate was obtained using following equation.

$$
\grave{\mathrm{i}}=\ln \left(N_{t} / N_{o}\right) / T_{t}-T_{o}
$$

Where, $N_{t}$ is the no of cells at the end of log phase; $N_{o}$ is the no of cells at the start of log phase; $T_{t}$ is the final day of $\log$ phase and $T_{o}$ is the starting day of log phase. If $\mathrm{T}$ expressed in days from the growth rate (i) can be converted to division or doublings per day $(\mathrm{k})$ by dividing $(\mu)$ by the natural log of 2(0.6931).

$$
\mathrm{K}=\mu / 0.6931
$$

Doubling time $\left(\mathrm{T}_{\mathrm{t}}\right)$ which is calculated by the following formula.

$$
\mathrm{T}_{\mathrm{t}}=0.6931 / \mathrm{i}
$$

\section{Lipid extraction}

After 6 days of growth in the fermenter the cells were harvested and collected by centrifugation, then dried at $80^{\circ} \mathrm{C}$ for $24-48 \mathrm{hrs}$. The resultant cells were disrupted for lipid extraction using organic solvent (dichloromethane: methanol (2:1) v/v solution) in Soxhlet apparatus for 3-4 hours followed by evaporation of the solvents. The total lipid was determined gravimetrically and hexane with small amount of water was added to the lipid fraction, vortexed and centrifuged. The supernatant was collected and the remaining residue was again washed with hexane. All hexane fractions were mixed and evaporated. The remaining substance was weighed as non-polar liquid whereas solid residue as polar fraction (Scarsella et al. 2010)

\section{Results and Discussion Isolation and identification of Chlorella vulgaris from various sites}

The distinct single algal colonies obtained after the spread plating of water samples were streaked on sterile BG11 and incubated. The algae obtained were characterized through microscopic observation and photomicrographs.

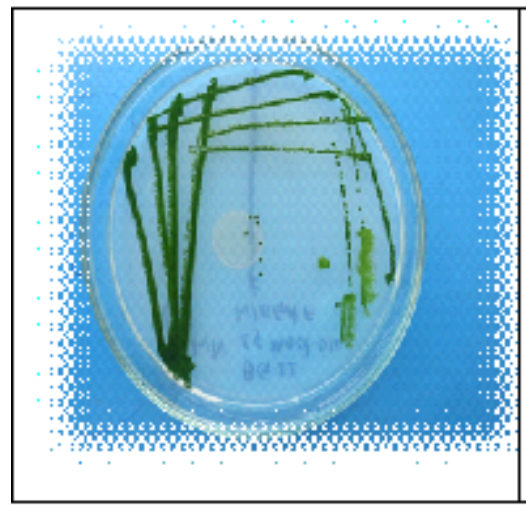

Photo 1. Streaking of single colony in BG11 Agar plate from Spread plate

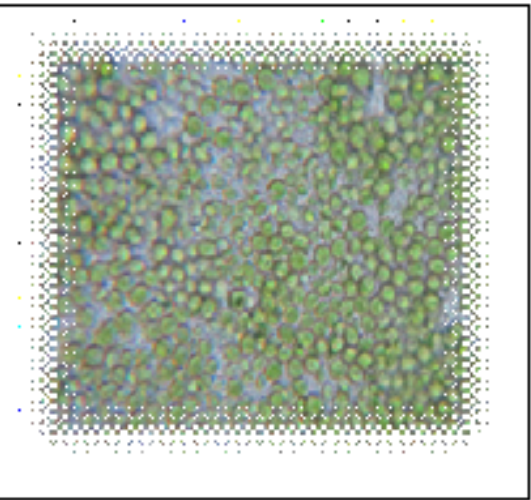

Photo 2. Microscopic observation of Cell under 40×Maginification

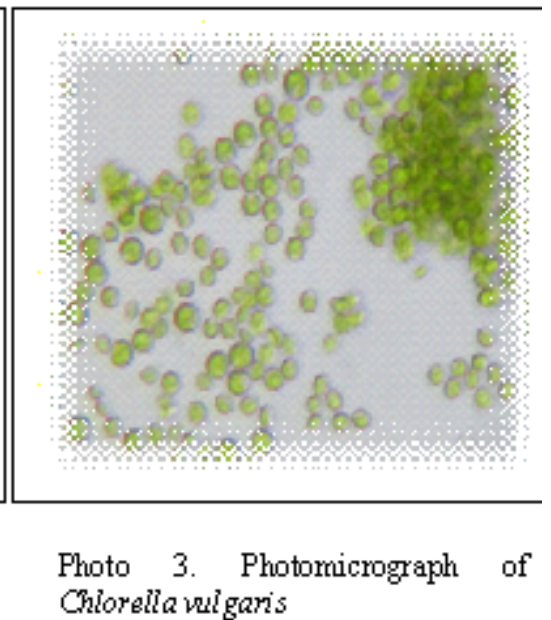




\section{pH optimization}

The optimum $\mathrm{pH}$ for $C$. vulgaris was found to be 7 (Figures 1-3). The highest OD value was 5.100 at 686 $\mathrm{nm}$ for $\mathrm{pH} 7$ along with highest cell count $\left(1.227 \times 10^{8}\right.$ cells/ ml) and dry weight of $3.34 \mathrm{~g} / \mathrm{l}$. According to Lustigman et al. (1995), it is desired to strive for $\mathrm{pH} 6$. However, our study showed that the optimum $\mathrm{pH}$ for C. vulgaris was $\mathrm{pH}$ 7. The difference in optimum $\mathrm{pH}$ obtained in our research and in the above mentioned research article was may be due to different strains and different culture conditions.

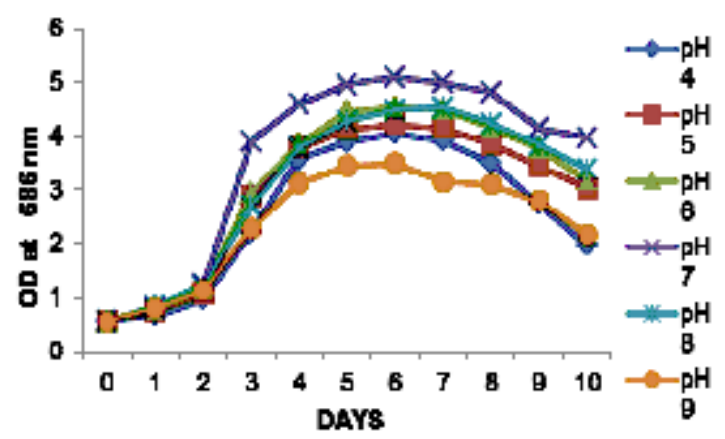

Fig. 1. Growth response of $C$. vulgaris at different $\mathrm{pH}$ (OD vs days)

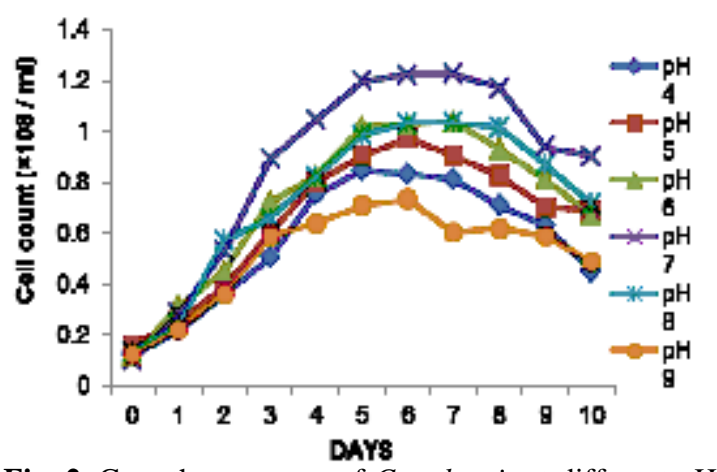

Fig. 2. Growth responses of $C$. vulgaris at different $\mathrm{pH}$ (Cell count vs.days

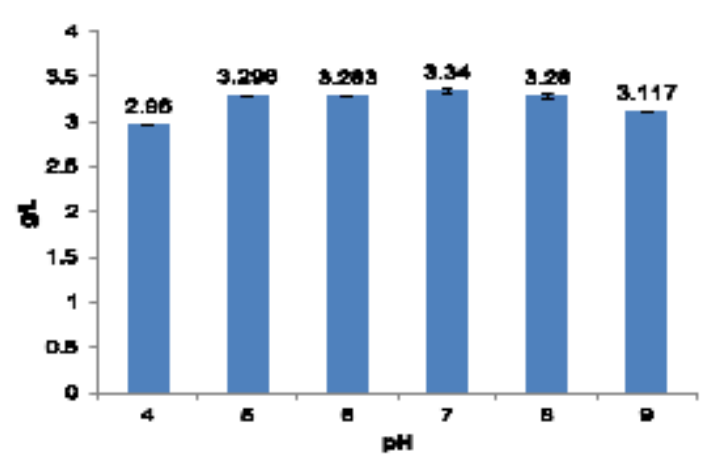

Fig. 3. Dry weight of cells in g/l vs. different $\mathrm{pH}$

\section{Selection of growth regimen}

The growth in mixotrophic culture was observed to be much higher than in autotrophic culture as shown in Fig. 4). This indicates that isolated $C$. vulgaris can grow both autotrophically and mixotrophically. In mixotrophic culture the cell grew so rapidly that the log phase started within $2^{\text {nd }}$ day and ended in $7^{\text {th }}$ day whereas in case of autotrophic culture the cell grew so slowly that even on obtaining the decline phase of mixotrophic culture, the log phase had not attained in autotrophic culture. Thus, the $C$. vulgaris showed the best growth at mixotrophic than autotrophic conditions. Hence, for the maximum growth within short a period of time, we chose the mixotrophic culture for our further study.

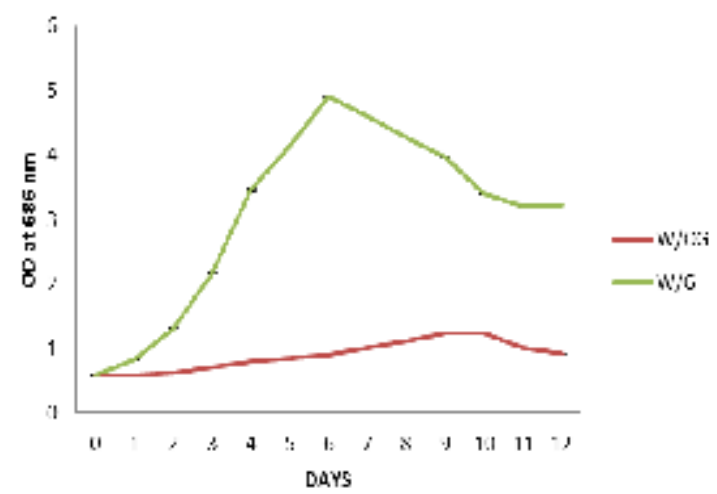

Fig. 4. Growth response of $C$. vulgaris in two different growth regimens. (OD vs days)

\section{Selection of nitrogen sources}

By observing the result of optical density (Fig. 5), cell count (Fig. 6) and dry weight (Fig. 7) in media containing different nitrogen sources, the highest growth was found in medium containing $\mathrm{NaNO}_{3}$.

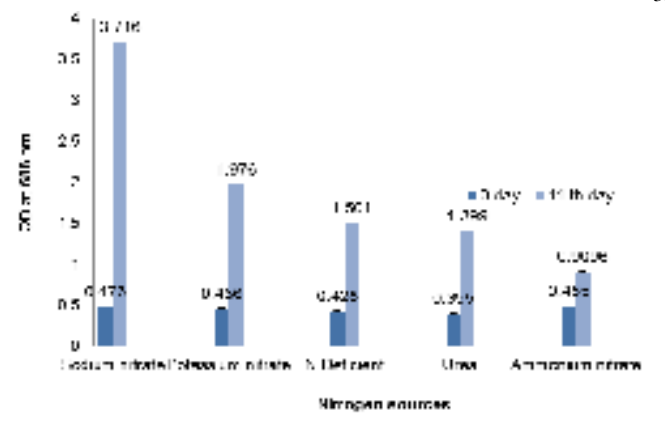

Fig. 5. Growth response of $C$. vulgaris with different Nitrogen sources (OD at $686 \mathrm{~nm}$ vs. days). 


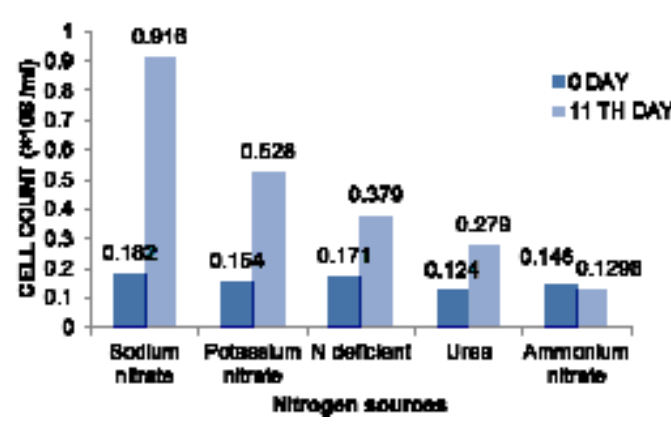

Fig. 6. Growth response of $C$. vulgaris with different Nitrogen sources (Cell count vs. days)

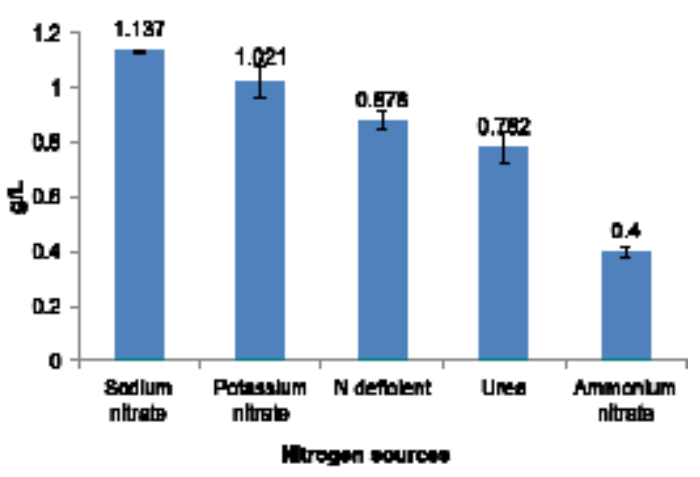

Fig. 7. Graph (with standard error) of dry weight of cells in gm. /L vs. different Nitrogen sources.

\section{Scale up and biomass production in fermenter}

The growth curve was plotted with respect to OD (Fig. 8), cell count (Fig. 9) and dry weight (Fig. 10). The growth rate was found to be 6.879 cells/ml/ day and doubling time was 2 hrs and 9 mins.

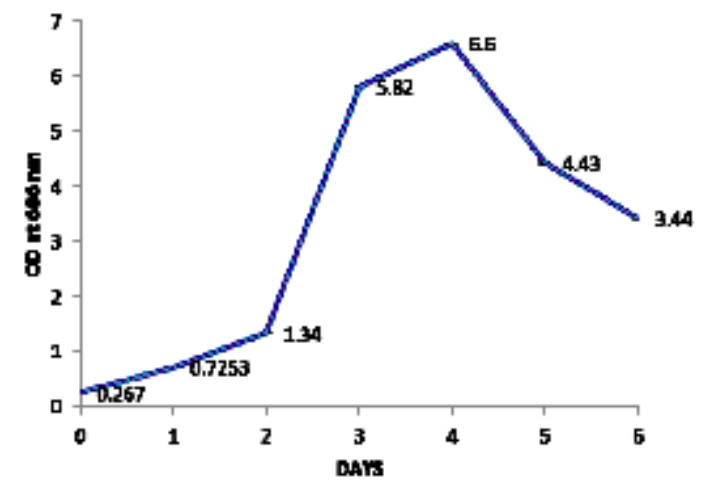

Fig. 8. Growth response of C. vulgaris in fermenter (OD vs days)

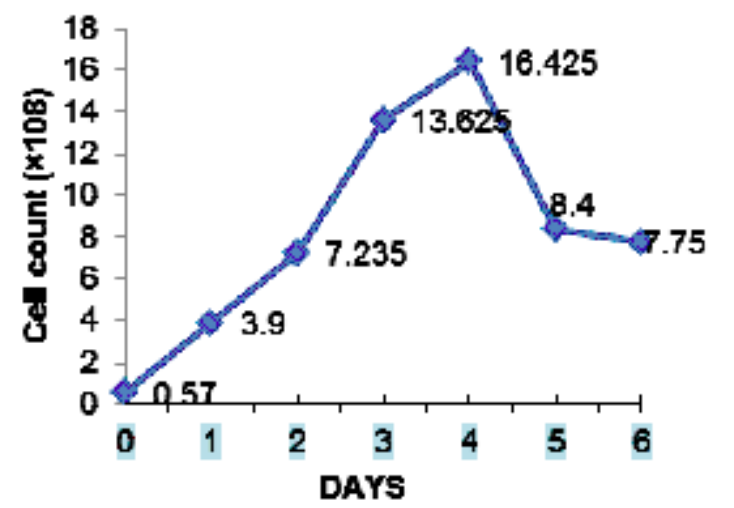

Fig. 9. Growth response of C.vulgaris in fermenter (Cell count vs. days)

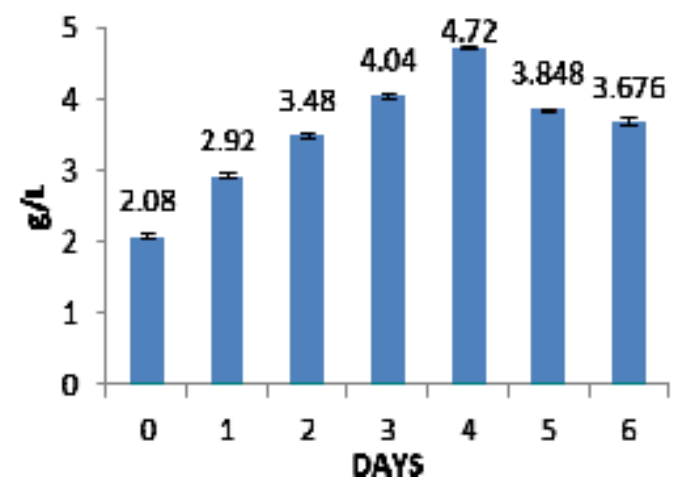

Fig. 10. Growth response of C. vulgaris in fermenter (Dry weight vs. days)

\section{Determination of growth rate}

After obtaining the growth kinetics of $C$. vulgaris in fermenter with controlled conditions as mentioned above, the specific growth rate and doubling time was determined by the formula given in the methodology. Then the specific growth rate and doubling time were obtained as 6.879 cells/ml/day and two hours and nine minutes respectively.

\section{Lipid extraction}

After the organic solvent extraction in Soxhlet extractor followed by evaporation of solvent, the total lipid obtained was $0.15533 \mathrm{~g} / \mathrm{g}$ dry weight of $C$. vulgaris. Total yield of total lipid obtained was $15.53 \%$. Similarly, after mixing with hexane and evaporation the non-polar lipid obtained was $0.066933 \mathrm{~g}$ / g dry weight.

Direct disruption of microalgae can result in efficeint biodiesel production (Anitha \& Shriman 2012). Hence 
Nepal Journal of Science and Technology Vol. 14, No. 2 (2013) 43-48

we can use chemical solvents, enzymes (lipase) or physical cell disrupter to release oil from microalgal cells.

\section{Acknowledgements}

Authors are thankful to the University Grant Commission, Nepal for the financial assistance. We would like to acknowledge the head of the Department of Biotechnology, Asian Institute of Technology and Management for the laboratory facilities.

\section{References}

Anitha, S. and N.J. Sriman. 2012 Biodiesel production from Chlorella vulgaris with special emphasis on immobilized lipase catalyzed tranesterification. International Journal of Recent Scientific Research l3(9): 733-737.

Belasco, W. 1997. Algae burgers for a hungry world? The rise and fall of Chlorella cuisine. Technology and Culture 38: 608-34.

Christi, Y. 2007. Biodiesel from microalgae. Biotechnology Advances 25: 294-306.

Dayananda, C., R. Sarada, V. Kumar and G.A. Ravishankar. 2007. Isolation and characterization of hydrocarbon producing green alga Botryococcus braunii from Indian freshwater bodies. Electronic Journal of Biotechnology 10 (1): 78-91

Edberg, A. 2010. Growth of Chlorella vulgaris at high carbon dioxide levels in Swedish light conditions. Laboratory testing and development of methods. MSc Thesis in Energy Engineering, Umeå Institute of Technology, Sweden.

Geeta, G.S. and H.V. Rani. 2011. Isolation of microalgae with biodiesel productivity prospects. Karnataka Journal of Agricultural Sciences 24(4): 585-588.

$\mathrm{Hu}$, Q., M. Sommerfeld, E. Jarvis, M. Ghirardi, M. Posewitz, M. Seibert and A. Darzins. 2008.
Microalgal triacylglycerols as feedstocks for biofuel production: perspective and advances. The Plant Journal 54: 621-639.

Illman, A.M., A.H. Scragg and S.W. Shales. 2000. Increase in Chlorella strains calorific values when grown in low nitrogen medium. Enzyme Microbial Technology 27: 631-635.

Khola, G. and B. Ghazala. 2009. Biodiesel production from algae. Pak. J. Bot. 44(1): 379-381.

Liang, Y., N. Sarkany and Y. Cui. 2009. Biomass and lipid productivities of Chlorella vulgaris under autotrophic, heterotrophic and mixotrophic growth conditions. Biotechnol. Lett. 31: 1043-1049.

Lustigman, B., L.H. Lee and A. Khalil. 1995. Effects of nickel and $\mathrm{pH}$ on the growth of Chlorella vulgaris. Bulletin of Environmental Contamination and Toxicology 55(1): 73-80.

Scarsella, M., G. Belotti, P. De Filippis and M. Bravi. 2010. Study on the optimal growing conditions of Chlorella vulgaris in bubble column photobioreactors. Department of Chemical Engineering Materials Environment, Sapienza University of Roma, Italy. Vol. 20. DOI:10.3303/ CET1020015.

Sharma, R., G.P. Singh and V.K. Sharma. 2011. Comparison of different media formulations on growth, morphology and chlorophyll content of green algae Chlorella vulgaris. International Journal of Pharmacy and Biological Sciences 2(2): 509-516.

Spolaore, P., C. Joannis-cassan, E. Duran and A. Isambert. 2006. Commercial applications of microalgae. Journal of Bioscience Bioengineering 101(2): 87-96.

Zelitch, I. 1971. Photosynthesis, photorespiration and plant productivity. Academic Press, New York.

Zhang, F., H. Kabeya, R. Kitagawa and T. Hirotsu. 2000. An exploratory research of PVC-Chlorella composite material (PCCM) as effective utilization of Chlorella biologically fixing $\mathrm{CO}_{2}$. Journal of Materials Science 35: 2603-2609 